\title{
Hexane extracts of garlic cloves induce apoptosis through the generation of reactive oxygen species in Hep3B human hepatocarcinoma cells
}

\author{
HYE JEONG KIM ${ }^{1}$, MIN HO HAN ${ }^{1,2}$, GI YOUNG KIM ${ }^{3}$, YOUNG-WHAN CHOI ${ }^{4}$ and YUNG HYUN CHOI ${ }^{1,2}$ \\ ${ }^{1}$ Department of Biochemistry, Dongeui University College of Oriental Medicine, Busan 614-052; \\ ${ }^{2}$ Department of Biomaterial Control (BK21 Program), Graduate School and Anti-Aging Research Center \\ and Blue-Bio Industry RIC, Dongeui University, Busan 614-714; ${ }^{3}$ Department of Marine Life Sciences, \\ Jeju National University, Jeju 690-756; ${ }^{4}$ Department of Horticultural Bioscience, College of Natural \\ Resource and Life Sciences, Busan National University, Miryang 627-706, Republic of Korea
}

Received May 7, 2012; Accepted June 27, 2012

DOI: 10.3892/or.2012.1985

\begin{abstract}
Garlic (Allium sativum) compounds have recently received increasing attention due to their cancer chemopreventive properties, and their anticancer activities are extensively reported in many cancer cell lines. However, the anticancer activity and the signaling pathway associated with the induction of apoptosis by extracts of garlic cloves have not been elucidated. In this study, we examined the effects of hexane extracts of garlic cloves (HEGCs) on reactive oxygen species (ROS) production and the association of these effects with apoptotic cell death, using a Hep3B human hepatocarcinoma cell line in vitro. The results demonstrated that HEGCs mediate ROS production, and that this mediation is followed by a collapse of mitochondrial membrane potential (MMP, $\Delta \Psi_{\mathrm{m}}$ ), the downregulation of anti-apoptotic Bcl-2 and Bcl-xL and the activation of caspase- 9 and -3. HEGCs also promoted the activation of caspase- 8 and the downregulation of Bid, a BH3-only pro-apoptotic member of the Bcl-2. However, the apoptotic phenomena displayed by HEGCs were significantly diminished by the presence of z-VAD-fmk (non-selective caspase inhibitor). Moreover, N-acetyl-L-cysteine (NAC), a widely used ROS scavenger, effectively blocked the HEGCinduced apoptotic effects via the inhibition of ROS production and MMP collapse. These observations clearly indicate that HEGC-induced ROS are key mediators of MMP collapse, which leads to the induction of apoptosis, followed by caspase activation.
\end{abstract}

Correspondence to: Dr Yung Hyun Choi, Department of Biochemistry, Dongeui University College of Oriental Medicine, Busan 614-052, Republic of Korea

E-mail: choiyh@deu.ac.kr

Key words: garlic cloves, apoptosis, reactive oxygen species, mitochondrial membrane potential

\section{Introduction}

In general, apoptosis may be initiated by either an extrinsic (death receptor-mediated) or an intrinsic (mitochondrialmediated) pathway. The extrinsic pathway functions via death receptors on the cell surface that may directly activate caspase-8. The intrinsic pathway regulates apoptotic cascades that occur as a result of the convergence of the signaling at the mitochondrion, which results in the alteration of the mitochondrial membrane potentials (MMP, $\Delta \Psi_{\mathrm{m}}$ ), the release of cytochrome $c$ into the cytosol and the activation of caspase-9 (1). Mitochondria are the major energy generators of adenosine triphosphate (ATP) by oxidative phosphorylation, and mitochondrial-mediated apoptosis occurs in response to a wide range of stimuli. Reactive oxygen species (ROS), which are the byproducts of normal cellular oxidative processes, are generated in and around mitochondria, and it has been suggested that they are involved in regulating the process involved in the initiation of apoptotic signaling (2-4). Therefore, constitutively elevated levels of cellular oxidative stress and the dependence on ROS signaling may represent a redox vulnerability of malignancies, which may be targeted by chemotherapeutic intervention using redox modulators; both anti- and prooxidant agents have been shown to exert anticancer activity $(5,6)$. Consistent with the role of mitochondria in the control of cell death, survival or apoptotic factors such as Bcl-2 and Bax act on the organelle to prevent or facilitate the release of apoptogenic factors, such as cytochrome $c(5-7)$.

Garlic (Allium sativum), used for both culinary and medical purposes in Asia for many years, has come under intensive study in the past few decades because of its ability to impart a beneficial effect on several human disease processes (8). Garlic derivatives have various biological properties, such as anti-inflammatory (9), antimicrobial (10), antithrombotic (11), antihypertensive (12), antihyperlipidemic (13), antihyperglycemic (8) and immune system enhancement (14). Moreover, recent studies have indicated that garlic compounds inhibit the growth of cancer cells, and that this inhibition of growth is associated with cell cycle arrest and the stimulation 
of apoptosis $(8,15-23)$. However, the biochemical mechanisms underlying garlic clove extract-induced apoptosis in cancer cells have not yet been explored.

The primary purpose of this study was to evaluate the role of mitochondria in apoptosis induced by hexane extracts of garlic cloves (HEGCs), using a Hep3B human hepatocarcinoma cell line. As such, we examined whether ROS were critical mediators of HEGC-induced Hep3B cell death and determined the sequence of events leading to the activation of downstream caspases and apoptosis. In this report, we present evidence that HEGCs elicit ROS, which in turn triggers a decrease in MMP, consequently leading to caspase activation.

\section{Materials and methods}

Plant materials and preparation of hexane extract. The garlic cloves were purchased directly from the Danyang Food Company in Danyang, Korea, in January 2009. The fresh garlic cloves $(100 \mathrm{~g})$ were macerated in a blender, extracted with $300 \mathrm{ml}$ of $80 \% \mathrm{MeOH} 3$ times, and then filtered with Whatman no. 2 filter paper. The extracted garlic solution was successively partitioned with $300 \mathrm{ml}$ of hexane, chloroform and n-butanol 3 times. The upper layer suspension was filtered and evaporated under reduced pressure at $45^{\circ} \mathrm{C}$ and then lyophilized. A yellow, oily residue of the hexane extract $(285 \mathrm{mg}$ ) was obtained. The remaining aqueous layer was partitioned again, with chloroform and n-butanol sequentially, to yield chloroform $(155 \mathrm{mg})$ and n-butanol extract fractions $(2,223 \mathrm{mg})$. HEGCs were used in this study. Hexane, chloroform, and methanol were purchased from Fisher Scientific, Ltd. (Pittsburgh, PA, USA).

Cell culture and viability assay. Hep3B cells were obtained from the American Type Culture Collection (Rockville, MD, USA). The cells were cultured in RPMI-1640 medium supplemented with $10 \%$ fetal bovine serum (FBS, Gibco-BRL, Gaithersburg, MD, USA) and $1 \%$ penicillin-streptomycin at $37^{\circ} \mathrm{C}$ in a humid environment containing $5 \% \mathrm{CO}_{2}$. For the cell viability study, Hep3B cells were grown to $70 \%$ confluence and treated with various concentrations of HEGCs. The control cells were supplemented with complete media containing $0.1 \%$ DMSO (vehicle control). Following treatment, cell viability was determined using the MTT assay, which is based on the conversion of MTT to MTT-formazan by mitochondrial enzymes. The effect of HEGCs on the inhibition of cell growth was assessed as the percentage of cell viability, where the vehicle-treated cells were considered $100 \%$ viable.

Nuclear staining with DAPI. After treating the cells with HEGCs for $48 \mathrm{~h}$, the cells were harvested, washed in ice-cold phosphatebuffered saline (PBS) and fixed with $3.7 \%$ paraformaldehyde (Sigma) in PBS for $10 \mathrm{~min}$ at room temperature. The fixed cells were washed with PBS and stained with a 4,6-diamidino2-phenylindole (DAPI, Sigma) solution for $10 \mathrm{~min}$ at room temperature. The nuclear morphology of the cells was examined using fluorescence microscopy (Carl Zeiss, Germany).

DNA fragmentation assay. The cells were treated with different concentrations of HEGCs for $48 \mathrm{~h}$ and lysed on ice in a buffer containing $10 \mathrm{mM}$ Tris- $\mathrm{HCl}$ (pH 7.4), $150 \mathrm{mM} \mathrm{NaCl}$,
$5 \mathrm{mM}$ EDTA and $0.5 \%$ Triton X-100 for $30 \mathrm{~min}$. The lysates were vortexed and cleared by centrifugation at $10,000 \mathrm{x} \mathrm{g}$ for $20 \mathrm{~min}$. The fragmented DNA in the supernatant was extracted using an equal volume of neutral phenol:chloroform:isoamyl alcohol (25:24:1, v/v/v) and analyzed electrophoretically on $1 \%$ agarose gel containing ethidium bromide (EtBr, Sigma) (24).

Flow cytometric analysis for measurement of sub-G1 phase. The cells were harvested and washed once with PBS, fixed in ice-cold $70 \%$ ethanol and stored at $4^{\circ} \mathrm{C}$. Prior to analysis, the cells were washed once again with PBS, suspended in $1 \mathrm{ml}$ of a cold propidium iodide (PI, Sigma) solution containing $100 \mu \mathrm{g} / \mathrm{ml}$ RNase A, $50 \mu \mathrm{g} / \mathrm{ml}$ PI, $0.1 \%$ (w/v) sodium citrate and $0.1 \%(\mathrm{v} / \mathrm{v}) \mathrm{NP}-40$, and further incubated on ice for $30 \mathrm{~min}$ in the dark. Flow cytometric analyses were carried out using a flow cytometer (FACSCalibur, Becton-Dickinson, San Jose, CA, USA). CellQuest software was used to determine the relative DNA content, based on the presence of a red fluorescence.

Measurement of intracellular ROS and MMP $\left(\Delta \Psi_{m}\right)$. ROS production was monitored using the stable non-polar dye 2,7 dichlorofluorescein diacetate (DCFH-DA), which readily diffuses into cells (25). The cells were seeded in 24-well plates and incubated in the absence or presence of HEGCs for different periods of time, after which they were incubated with $10 \mu \mathrm{M}$ DCFH-DA for $30 \mathrm{~min}$. ROS production in the cells was monitored using a flow cytometer with CellQuest Software. To measure the MMP, the dual-emission potential-sensitive probe $5,5 \mathrm{~V}, 6,6 \mathrm{~V}$-tetrachloro-1,1V,3,3 V-tetraethyl-imidacarbocyanine iodide (JC-1, Sigma), was used. After treatment with HEGC, $5 \times 10^{5}$ cells were collected, stained with $2 \mathrm{mg} / 1 \mathrm{JC}-1$ at $37^{\circ} \mathrm{C}$ for $20 \mathrm{~min}$ and then analyzed with a flow cytometer (26).

Protein extraction and western blotting. The cells were harvested and lysed. The protein concentrations were measured using a Bio-Rad protein assay (Bio-Rad Laboratories, Hercules, CA, USA), according to the manufacturer's instructions. For western blot analysis, an equal amount of protein was subjected to electrophoresis on SDS-polyacrylamide gel and transferred by electroblotting onto a nitrocellulose membrane (Schleicher \& Schuell, Keene, NH, USA). The blots were probed with the desired antibodies for $1 \mathrm{~h}$, incubated with the diluted enzyme-linked secondary antibody and visualized by enhanced chemiluminescence (ECL), according to the manufacturer's instructions (Amersham Corp., Arlington Heights, IL, USA). The primary antibodies were purchased from Santa Cruz Biotechnology Inc. (Santa Cruz, CA, USA) and Cell Signaling Technology, Inc. (Boston, MA, USA). The peroxidase-labeled donkey anti-rabbit immunoglobulin and peroxidase-labeled sheep anti-mouse immunoglobulin were purchased from Amersham Corp. (27).

In vitro caspase activity assay. Caspase activity was determined by a colorimetric assay using a caspase-3, -8 and -9 activation kit, according to the manufacturer's instructions (R\&D Systems, Minneapolis, MN, USA). Briefly, the cells were lysed in a lysis buffer for $30 \mathrm{~min}$ in an ice bath. The supernatants were collected and incubated at $37^{\circ} \mathrm{C}$ with the reaction buffer supplied, which contained dithiothreitol and 
A

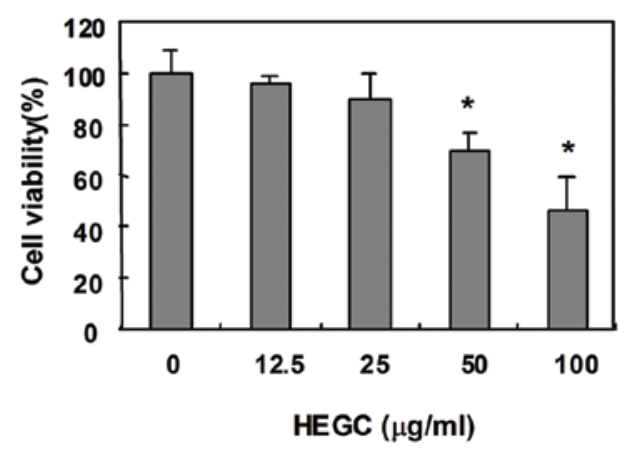

B

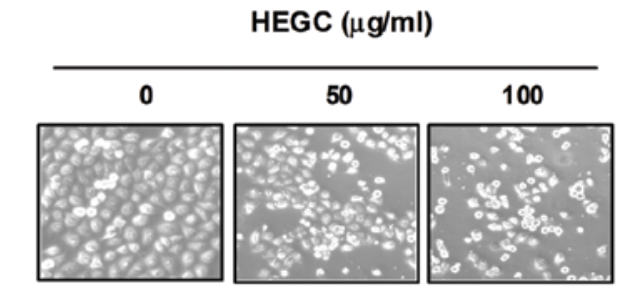

C

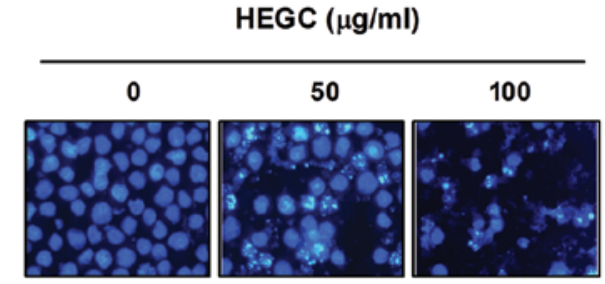

D

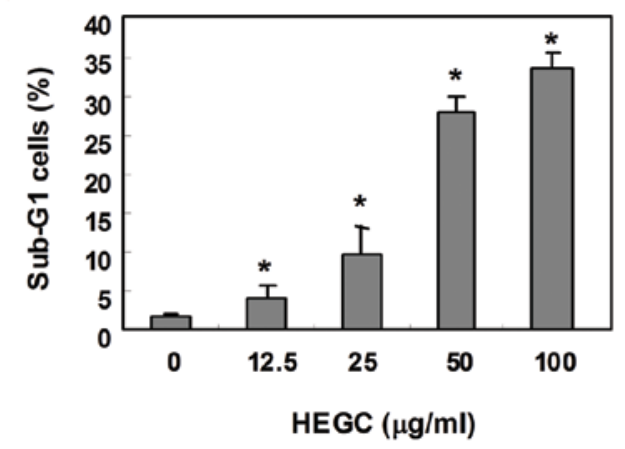

Figure 1. Inhibition of cell viability and induction of apoptosis by hexane extracts of garlic cloves (HEGCs) in Hep3B human hepatocarcinoma cells. (A) Cells were plated at a concentration of $1 \times 10^{5}$ cells $/ 60-\mathrm{mm}$ plate and then incubated for $24 \mathrm{~h}$. Next, the cells were treated with various concentrations of HEGCs for $48 \mathrm{~h}$, and cell viability was measured by the metabolic dye-based MTT assay. Data are the means \pm SD of 3 different experiments. The significance was determined by a Student's t-test $\left({ }^{*} \mathrm{P}<0.05\right.$, compared with the control). (B and C) The cellular (B) and nuclear (C) morphological changes in cells incubated with or without HEGCs for $48 \mathrm{~h}$ were examined under inverted (x200) and fluorescence microscopes (x400), respectively. (C) The cells were fixed and stained with DAPI solution for $10 \mathrm{~min}$ at room temperature. The results presented are from 1 representative experiment of the 3 performed, showing similar patterns. (D) To quantify the degree of apoptosis induced by HEGCs, the cells grown under the same conditions were evaluated for sub-G1 DNA content, which represents the fractions undergoing apoptotic DNA degradation, using a flow cytometer. Each point represents the means \pm SD of the representative experiments performed at least 3 times. The significance was determined by a Student's t-test ( ${ }^{*} \mathrm{P}<0.05$, compared with the control).

substrates, Asp-Glu-Val-Asp (DEVD)-p-nitroaniline (pNA) for caspase-3, Ile-Glu-Thr-Asp (IETD)-pNA for caspase-8 and Leu-Glu-His-Asp (LEHD)-pNA for caspase-9. The optical density of the reaction mixture was quantified spectrophotometrically at a wavelength of $405 \mathrm{~nm}$ (28).

Statistical analysis. The data are expressed as the means \pm SD. A statistical comparison was performed using one-way ANOVA, followed by a Fisher's test. The significant differences between the groups were determined using an unpaired Student's t-test. A P-value $<0.05$ was considered to indicate a statistically significant difference.

\section{Results}

HEGCs induce apoptosis in Hep3B cells. In order to evaluate the ability of HEGCs to inhibit the growth of Hep3B cells, the cells were exposed to different concentrations of HEGCs, after which MTT assays were performed. After being cultured in the presence of 50 and $100 \mu \mathrm{g} / \mathrm{ml} \mathrm{HEGC} \mathrm{for} 48 \mathrm{~h}$, cell viability decreased by $\sim 70$ and $58 \%$, respectively, when compared to that of the controls (Fig. 1A), which was associated with characteristic features of cell shrinking, rounding and detachment (Fig. 1B). Further experiments were then conducted to determine whether HEGCs inhibit the proliferation of Hep3B cells through the induction of apoptosis. As shown in Fig. 1C, DAPI staining revealed that the number of nuclei showing chromatin condensation and the formation of apoptotic bodies increased in cells cultured with HEGCs in a concentration-dependent manner. Therefore, the degree of apoptosis was determined by analyzing the amount of sub-G1 DNA that was in the cells treated with HEGCs, using a flow cytometer. As shown in Fig. 1D, the addition of HEGCs resulted in the increased accumulation of cells in the sub-G1 phase, which was similar to the results observed in the HEGC-induced loss of cell viability and formation of apoptotic bodies. These results indicated that HEGCs inhibit the proliferation of Hep3B cells through the induction of apoptosis.

Modulation of Bcl-2 family proteins and loss of MMP by HEGCs in Hep3B cells. The role of the mitochondria in HEGC-induced apoptosis of Hep3B cells was investigated by examining the effect of HEGCs on the levels of the Bcl-2 family proteins, as well as the MMP values. As shown in Fig. 2A, the protein levels of anti-apoptotic Bcl-2 and Bcl-xL were decreased in a concentration-dependent manner in response to HEGC treatment; however, the protein levels of pro-apoptotic Bax remained unchanged. Under these conditions, the levels of total pro-apoptotic protein $\mathrm{Bid}$, a $\mathrm{BH} 3$-only pro-apoptotic member of the Bcl-2 family, also decreased in response to HEGC treatment, in a concentration-dependent manner. To examine the role of mitochondria in apoptosis induced by HEGCs, we analyzed the profiles of the MMP values via a flow cytometer, using the mitochondrial-specific probe JC-1. As depicted in Fig. 2B, a loss of MMP was observed with an increased concentration of HEGCs, indicating that HEGCs induced mitochondrial dysfunction through the disruption of the outer mitochondrial membrane. 
A

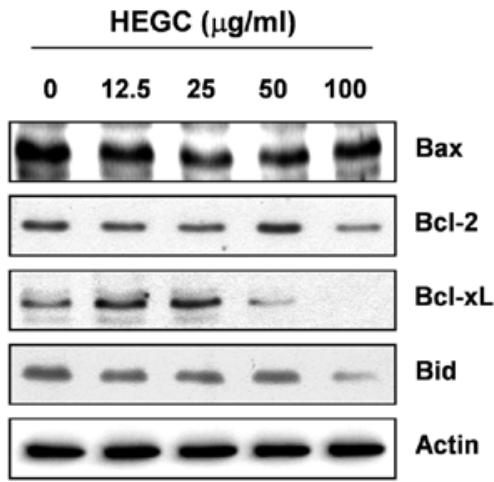

B

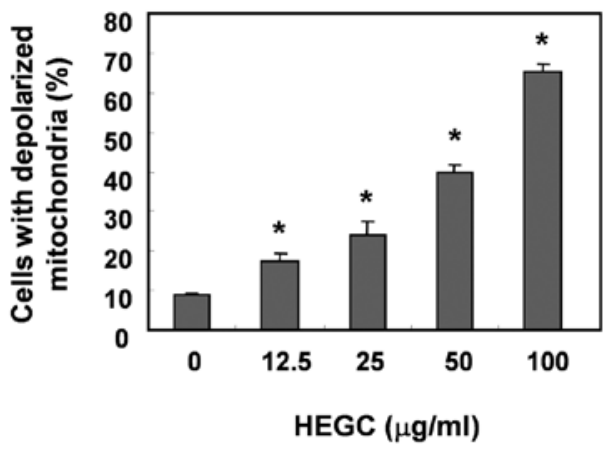

Figure 2. Effects of HEGC on the levels of the Bcl-2 family proteins and the values of MMP in Hep3B cells. (A) The cells were treated with the indicated concentrations of HEGCs for $48 \mathrm{~h}$. Equal amounts of cell lysates (30 $\mu \mathrm{g})$ were then resolved by SDS-polyacrylamide gels, transferred onto nitrocellulose membranes and probed with the indicated antibodies. The proteins were then visualized using ECL detection. Actin was used as the internal control. (B) The cells grown under the same conditions as those in (A) were stained with $\mathrm{JC}-1$ for $20 \mathrm{~min}$ at $37^{\circ} \mathrm{C}$. The mean JC-1 fluorescence intensity was then detected using a flow cytometer. Data are the means \pm SD of 3 different experiments. The significance was determined by a Student's t-test ("P $<0.05$, compared with control).

A

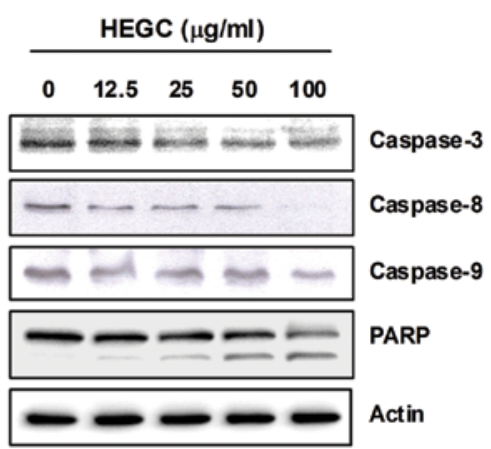

B

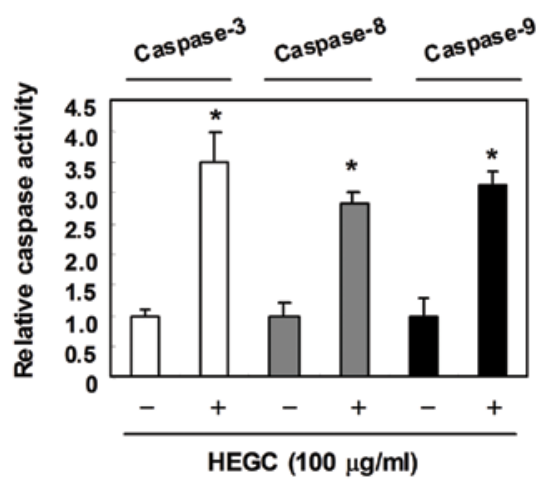

C

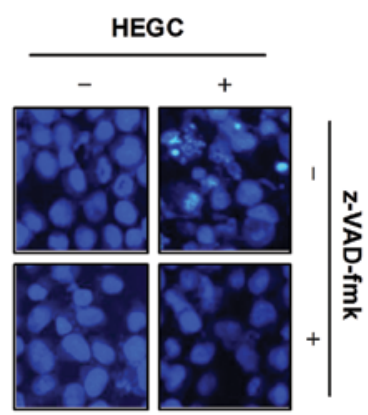

D

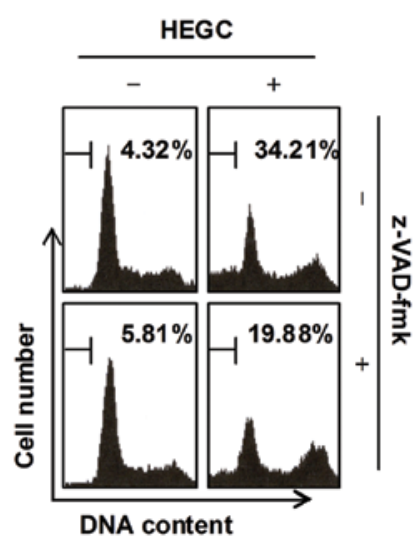

Figure 3. Activation of caspases by HEGC treatment in Hep3B cells. (A) The cells were treated with the indicated concentrations of HEGCs for $48 \mathrm{~h}$. Equal amounts of cell lysates $(30 \mu \mathrm{g})$ were resolved by SDS-polyacrylamide gels, transferred to nitrocellulose membranes and probed with antibodies against caspase-3, -8 and -9 and PARP. The proteins were then visualized using ECL detection. Actin was used as the internal control. (B) The cell lysates obtained from cells treated with or without $100 \mu \mathrm{g} / \mathrm{ml}$ HEGC for $48 \mathrm{~h}$ were assayed for in vitro caspase-3, -8 and -9 activity, using DEVD-pNA, IETD-pNA and LEHD-pNA, respectively, as substrates. The relative fluorescent products were measured. Data are the means \pm SD from the representative experiments performed at least 3 times. The significance was determined by a Student's t-test ("P $<0.05$, compared with the control). (C) The cells were incubated with or without $100 \mu \mathrm{g} / \mathrm{ml}$ HEGC for $48 \mathrm{~h}$ after $1 \mathrm{~h}$ pretreatment with or without $50 \mu \mathrm{M}$ of pan-caspase inhibitors (z-VAD-fmk) and then stained with DAPI for 10 min and images were captured with a fluorescence microscope using a blue filter (x400). (D) DNA contents of cells grown under the same conditions as (C) were analyzed by a flow cytometer. Each point represents the average of 2 independent experiments.

Activation of caspases by HEGCs in Hep3B cells. In order to determine if HEGC-induced apoptosis is associated with the activation of caspases, the expression and activity of caspases such as capases-3, -8 and -9 in the HEGC-treated cells were examined using western blot analysis and an in vitro activity assay. As shown in Fig. 3A and B, the HEGC treatment decreased the expression levels of pro-caspase- $3,-8$ and -9 in a concentration-dependent manner, and increased the in vitro activity of those caspases and concomitant degradation of poly(ADP-ribose) polymerase (PARP), which is a substrate protein of caspase-3. In order to demonstrate that the activation of caspases is a key step in the apoptotic pathway induced by 
A

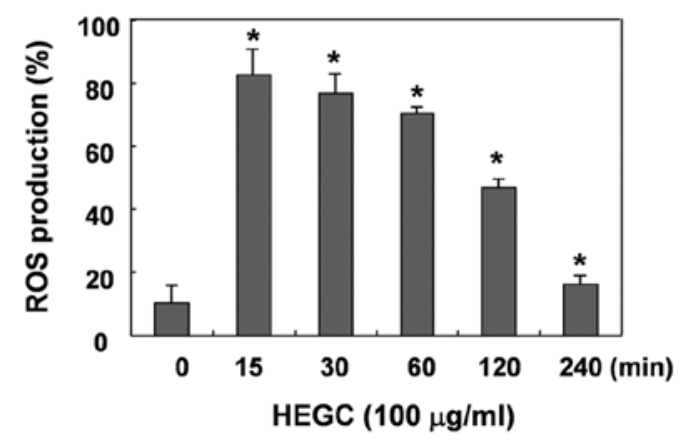

B

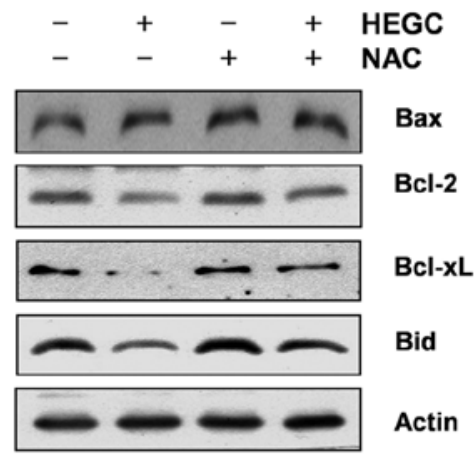

C

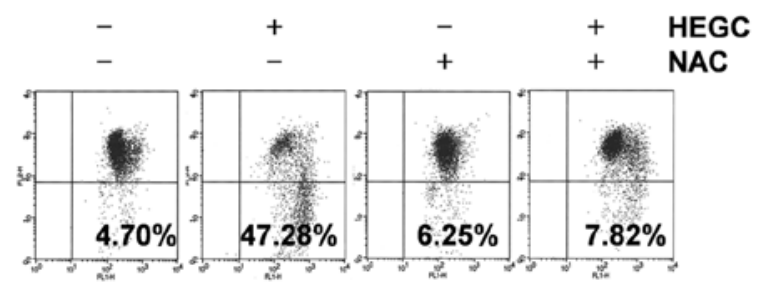

Figure 4. HEGC-induced modulation of the Bcl-2 family proteins and loss of MMP are associated with ROS generation in Hep3B cells. (A) The cells were treated with $100 \mu \mathrm{g} / \mathrm{ml}$ HEGC for the indicated times, stained with DCFH-DA and incubated at $37^{\circ} \mathrm{C}$ for $30 \mathrm{~min}$. At each time point, the fluorescent intensity was measured using a flow cytometer. Data are the means \pm SD of 3 different experiments. The significance was determined by a Student's t-test ( $\mathrm{P}<0.05$, compared with the control). (B) Cells were treated with or without NAC $(10 \mathrm{mM})$ for $1 \mathrm{~h}$ before treatment with $100 \mu \mathrm{g} / \mathrm{ml}$ of HEGCs for $48 \mathrm{~h}$ and then the cellular proteins were isolated. Equal amounts of cell lysates $(30 \mu \mathrm{g})$ were resolved by SDS-polyacrylamide gels, transferred onto nitrocellulose membranes and probed with the indicated antibodies. The proteins were then visualized using ECL detection. Actin was used as the internal control. (C) Cells were treated with or without NAC (10 mM) for $1 \mathrm{~h}$ before treatment with $100 \mu \mathrm{g} / \mathrm{ml}$ of HEGCs for $2 \mathrm{~h}$, and then stained with JC-1 and incubated at $37^{\circ} \mathrm{C}$ for $20 \mathrm{~min}$. The mean JC-1 fluorescence intensity was detected using a flow cytometer. Data represent the average of 2 independent experiments.

HEGCs, Hep3B cells were pretreated for $1 \mathrm{~h}$ with z-VAD-fmk, a cell-permeable pan-caspase inhibitor, followed by treatment with HEGCs. As shown in Fig. 3C and D, pretreatment of the cells with z-VAD-fmk significantly blocked the chromatin condensation and an increase in the sub-G1 population induced by HEGCs, indicating that HEGC-induced apoptosis is caspase-dependent.

HEGC-induced mitochondrial dysfunction is associated with the generation of intracellular ROS. Since generation and acumination of ROS in cancer cells may be related to mitochondrial dysfunction and cell apoptosis, we attempted to characterize the correlation between ROS production and changes in the MMP. For this investigation, we performed kinetic studies to evaluate HEGC-stimulated intracellular ROS productions, which were measured by using the cellpermeant oxidation-sensitive dye DCFH-DA. As shown in Fig. 4A, ROS generation increased significantly, as early as $15 \mathrm{~min}$ and began to decrease afterwards, eventually dropping below the untreated control level at $4 \mathrm{~h}$. We reasoned that if ROS were a crucial factor in the induction of mitochondrial dysfunction by HEGCs, the inhibition of ROS generation must abrogate the loss of MMP. Therefore, cells were pretreated for $1 \mathrm{~h}$ with $10 \mathrm{mM} \mathrm{N}$-acetyl-L-cysteine (NAC), a commonly used reactive oxygen intermediate scavenger, and then treated with HEGCs. As shown in Fig. 4C, HEGC-induced loss of MMP in Hep3B cells that were co-cultured with NAC was effectively blocked, indicating that rapidly and transiently produced ROS are capable of triggering mitochondrial dysfunction. In addition, blocking the generation of ROS by pretreatment of the cells with NAC prevented the HEGC-induced downregulation of $\mathrm{Bcl}-2$ and $\mathrm{Bcl}-\mathrm{xL}$ expression and a decrease in the Bid protein (Fig. 4B).

HEGC-induced caspase activation is associated with the generation of intracellular ROS. To determine whether ROS generation is involved in HEGC-induced caspase activation, the cells were pretreated with NAC for $1 \mathrm{~h}$ and then exposed to $100 \mu \mathrm{g} / \mathrm{ml} \mathrm{HEGC}$ for $6 \mathrm{~h}$ to determine the expression levels of caspase- $3,-8$ and -9 , as well as their activities. As shown in Fig. 5A and B, blocking the generation of ROS by pretreatment of the cells with NAC prevented the HEGC-induced caspase activation, as well as the degradation of PARP protein. Furthermore, the presence of NAC almost completely suppressed the HEGC-induced chromatin condensation and apoptotic ratio (Fig. 5C and D). Thus, our data indicate that HEGCs may cause apoptosis in Hep3B cells through a ROS-mediated pathway.

\section{Discussion}

An increasing amount of data show that the potential of antitumor activity of garlic compounds may be mediated through a mitochondria-caspase-dependent pathway $(16-18,20,21)$. However, the signaling pathway associated with the induction of apoptosis by extracts of garlic cloves is poorly defined. In the course of our screening program of bioactive products from garlic, we isolated HEGCs and demonstrated that HEGCs induced apoptosis in Hep3B hepatocarcinoma cells through the generation of ROS. Furthermore, we showed that HEGCinduced ROS generation was accompanied by the disruption of the MMP, which led to the activation of caspase-9, and eventually to cell death. In addition, the quenching of ROS generation by NAC, a ROS scavenger, was shown to prevent ROS generation and to confer almost complete protection against HEGC-induced MMP disruption and apoptosis. Taken together, these results suggest that ROS act upstream, signaling molecules to initiate apoptosis.

Mitochondria are a rich source of ROS, which are toxic byproducts of aerobic cells. ROS play an important role in cell proliferation, inflammation and cancer development. However, 
A

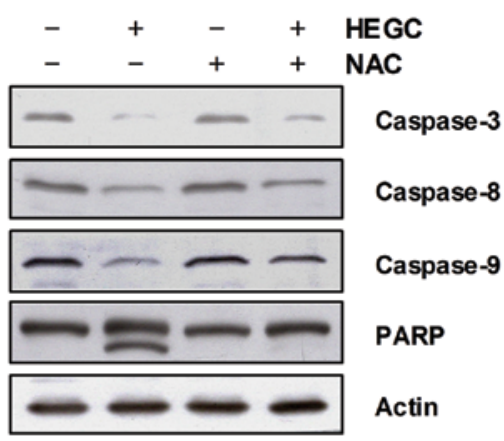

B

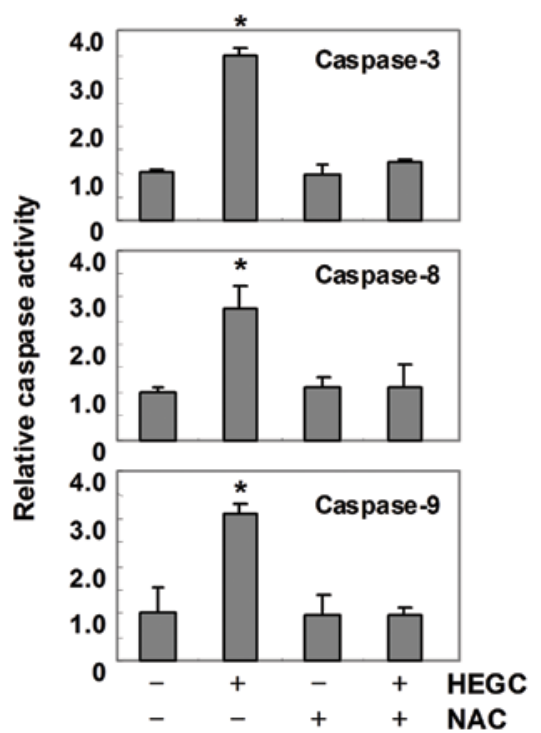

C

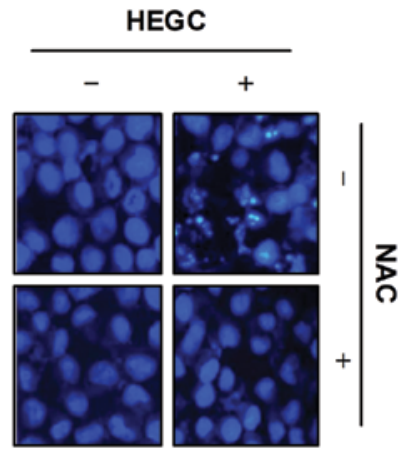

D

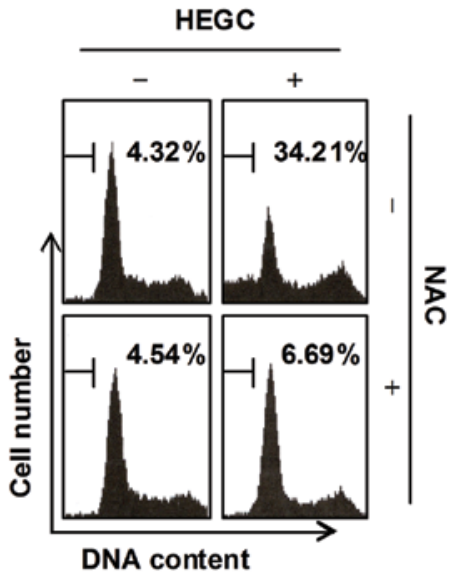

Figure 5. HEGC-induced activation of caspases and apoptosis are associated with ROS generation in Hep3B cells. (A) Cells were treated with or without NAC $(10 \mathrm{mM})$ for $1 \mathrm{~h}$ before treatment with $100 \mu \mathrm{g} / \mathrm{ml}$ of HEGCs for $48 \mathrm{~h}$. The cellular proteins were extracted, separated by SDS-polyacrylamide gels, and transferred onto nitrocellulose membranes. The membranes were probed with the indicated antibodies. Proteins were visualized using an ECL detection system. Actin was used as the internal control. (B) The cell lysates obtained from cells grown under the same conditions as (A) those assayed for in vitro caspase-3, -8 and -9 activity, using DEVD-pNA, IETD-pNA and LEHD-pNA, respectively, as substrates. The relative concentrations of the fluorescent products released were then measured. The results are expressed as the means \pm SD of 3 independent experiments. The significance was determined by a Student's t-test ( $\mathrm{P}<0.05$, compared with control). (C) The cells were incubated with or without $100 \mu \mathrm{g} / \mathrm{ml}$ of HEGC for $48 \mathrm{~h}$ after $1 \mathrm{~h}$ pretreatment with or without $\mathrm{NAC}$ (10 mM), and then stained with DAPI for 10 min and images were captured with a fluorescence microscope using a blue filter (x400). (D) The cells under the same conditions as (C) were evaluated for sub-G1 DNA content, using a flow cytometer. Results represent the means of 2 independent experiments.

an excessive amount of ROS may lead to cell death by apoptosis or necrosis (2-4). Recent investigations have suggested that damaged mitochondria stimulate increased ROS production, which subsequently activates the signaling pathways that control cancer cell growth. However, the loss of MMP as a result of mitochondrial depolarization in association with apoptosis appears to be more common. This decrease in the MMP causes disruption of the outer mitochondrial membrane and contributes to the release of cytochrome $c$. Furthermore, the release of cytochrome $c$ has been reported to contribute to the activation of caspase-9, which in turn causes activation of caspase-3 $(5,6,29)$. Many studies have demonstrated that the Bcl-2 family proteins regulate apoptosis either as an activator (Bax) or inhibitor (Bcl-2 and Bcl-xL) and the Bax/ $\mathrm{Bcl}-2$ or Bcl-2 ratio is considered a key factor in regulating the apoptotic process. Bcl-2 forms ion channels in mitochondrial membranes, and its ion channel activity may control apoptosis by influencing permeability in the intracellular membranes $(30,31)$. In this study, we observed that the MMP levels in Hep3B cells decreased after HEGC treatment (Fig. 2B), the activity of caspase- 9 and -3 increased and the PARP proteins, the substrate of caspase-3, were cleaved (Fig. 3). Our data also demonstrated that HEGC-induced apoptosis is related to the downregulation of anti-apoptotic Bcl-2 and $\mathrm{Bcl}-\mathrm{xL}$, without altering Bax levels, indicating that HEGCs may increase the Bax/Bcl-2 or Bcl-2 ratio (Fig. 2) and that induced mitochondrial dysfunction leads to the apoptosis of Hep3B cells. However, blocking caspase activity by pretreating the cells with a pan-caspase inhibitor, z-VAD-fmk, prevented HEGCinduced chromatin condensation and an increase in the sub-G1 population (Fig. 3), indicating that HEGCs induced apoptosis in a caspase-dependent manner. Further experiments showed that the HEGC treatment significantly increased the ROS-dependent activation of caspase- 9 and -3 and degradation of PARP, indicating the existence of mitochondrial-mediated caspase- 3 activity. The results demonstrated that HEGCs are capable of inducing mitochondrial dysfunction through ROS generation.

The present study also revealed that the activation of caspase-8 in HEGC-treated cells is ROS-dependent (Fig. 5), 
which suggests that ROS may act upstream of caspase- 8 activation in Hep3B cells. Therefore, it is reasonable to assume that the initial signal for the activation of caspase-8 after treatment with HEGCs also derives from ROS. Caspase- 8 activation causes cleavage of $\mathrm{Bid}$, which is a $\mathrm{BH} 3$-only pro-apoptotic Bcl-2 family member exclusively localized in the cytoplasm. The cleaved Bid, however, translocates to the mitochondria and triggers cytochrome $\mathrm{c}$ release, which leads to the activation of caspase-9 $(5,7)$. In this study, we aimed to determine whether or not HEGC-induced apoptosis is regulated by Bid. To accomplish this, we examined Bid cleavage and found that treatment of Hep3B cells with HEGCs resulted in the downregulation of the total Bid expression that was perfectly blocked by NAC pretreatment. Based on these observations, we conclude that the Bid protein is involved in the regulation of HEGC-induced apoptosis of Hep3B cells, and that this regulation also occurs in a ROS-dependent manner.

In conclusion, the present study demonstrates that Hep3B cells undergo apoptosis in response to treatment with HEGCs, which occurs through a mitochondrial-mediated pathway that requires ROS generation upstream to disrupt the MMP, leading to the activation of caspase- 9 and -8 . Our data emphasize the key role of ROS in apoptosis induced by HEGCs in hepatocarcinoma cells and indicate that a positive correlation exists between ROS and mitochondrial events leading to apoptosis.

\section{Acknowledgements}

This study was supported by a grant (code \#7-19-42) from the Rural Development Administration, Republic of Korea.

\section{References}

1. Chowdhury I, Tharakan B and Bhat GK: Current concepts in apoptosis: the physiological suicide program revisited. Cell Mol Biol Lett 11: 506-525, 2006.

2. Waldbaum S and Patel M: Mitochondria, oxidative stress, and temporal lobe epilepsy. Epilepsy Res 88: 23-45, 2010.

3. Stowe DF and Camara AK: Mitochondrial reactive oxygen species production in excitable cells: modulators of mitochondrial and cell function. Antioxid Redox Signal 11: 1373-1414, 2009.

4. Matés JM, Segura JA, Alonso FJ and Márquez J: Intracellular redox status and oxidative stress: implications for cell proliferation, apoptosis, and carcinogenesis. Arch Toxicol 82: 273-299, 2008.

5. Mohamad N, Gutierrez A, Nunez M, Cocca C, Martin G, Cricco G, Medina V, Rivera E and Bergoc R: Mitochondrial apoptotic pathways. Biocell 29: 149-161, 2005.

6. Orrenius S, Gogvadze V and Zhivotovsky B: Mitochondrial oxidative stress: implications for cell death. Annu Rev Pharmacol Toxicol 47: 143-183, 2007.

7. Yin XM: Signal transduction mediated by Bid, a pro-death Bcl-2 family proteins, connects the death receptor and mitochondria apoptosis pathways. Cell Res 10: 161-167, 2000.

8. Alpers DH: Garlic and its potential for prevention of colorectal cancer and other conditions. Curr Opin Gastroenterol 25: $116-121,2009$

9. Hodge G, Hodge S and Han P: Allium sativum (garlic) suppresses leukocyte inflammatory cytokine production in vitro: potential therapeutic use in the treatment of inflammatory bowel disease. Cytometry 48: 209-215, 2002.

10. Cellini L, Campli ED and Masulli M: Inhibition of Helicobacter pylori by garlic extract (Allium sativum). FEMS Immunol Med Microbiol 13: 273-277, 1996.
11. Bordia T, Mohammed N and Thomson M: An evaluation of garlic and onion as antithrombotic agents. Prostaglandins Leukot Essent Fatty Acids 54: 183-186, 1996.

12. McMahon FG and Vargas R: Can garlic lower blood pressure? A pilot study. Pharmacotherapy 13: 406-407, 1993.

13. Yeh YY and Yeh SM: Garlic reduces plasma lipids by inhibiting hepatic cholesterol and triacylglycerol synthesis. Lipids 29: 189-193, 1994.

14. Patya M, Zahalka MA, Vanichkin A, Rabinkov A, Miron T, Mirelman D, Wilchek M, Lander HM and Novogrodsky A: Allicin stimulates lymphocytes and elicits an antitumor effect: a possible role of p21ras. Int Immunol 16: 275-281, 2004.

15. Thomson $\mathrm{M}$ and Ali M: Garlic [Allium sativum]: a review of its potential use as an anti-cancer agent. Curr Cancer Drug Targets 3: 67-81, 2003.

16. Wu PP, Chung HW, Liu KC, Wu RS, Yang JS, Tang NY, Lo C Hsia TC, Yu CC, Chueh FS, et al: Diallyl sulfide induces cell cycle arrest and apoptosis in HeLa human cervical cancer cells through the p53, caspase- and mitochondria-dependent pathways. Int J Oncol 38: 1605-1613, 2011.

17. Nagaraj NS, Anilakumar KR and Singh OV: Diallyl disulfide causes caspase-dependent apoptosis in human cancer cells through a Bax-triggered mitochondrial pathway. J Nutr Biochem 21: 405-412, 2010.

18. Karmakar S, Banik NL, Patel SJ and Ray SK: Garlic compounds induced calpain and intrinsic caspase cascade for apoptosis in human malignant neuroblastoma SH-SY5Y cells. Apoptosis 12: 671-684, 2007.

19. Karmakar S, Choudhury SR, Banik NL and Ray SK: Molecular mechanisms of anti-cancer action of garlic compounds in neuroblastoma. Anticancer Agents Med Chem 11: 398-407, 2011.

20. Su CC, Chen GW, Tan TW, Lin JG and Chung JG: Crude extract of garlic induced caspase-3 gene expression leading to apoptosis in human colon cancer cells. In Vivo 20: 85-90, 2006.

21. Xiao D, Pinto JT, Gundersen GG and Weinstein IB: Effects of a series of organosulfur compounds on mitotic arrest and induction of apoptosis in colon cancer cells. Mol Cancer Ther 4: 1388-1398, 2005.

22. Herman-Antosiewicz A, Powolny AA and Singh SV: Molecular targets of cancer chemoprevention by garlic-derived organosulfides. Acta Pharmacol Sin 28: 1355-1364, 2007.

23. Herman-Antosiewicz A and Singh SV: Signal transduction pathways leading to cell cycle arrest and apoptosis induction in cancer cells by Allium vegetable-derived organosulfur compounds: a review. Mutat Res 555: 121-131, 2004.

24. An SH, Kang JH, Kim DH and Lee MS: Vitamin C increases the apoptosis via up-regulation p53 during cisplatin treatment in human colon cancer cells. BMB Rep 44: 211-216, 2011.

25. Cathcart R, Schwiers E and Ames BN: Detection of picomole levels of lipid hydroperoxides using a dichlorofluorescein fluorescent assay. Methods Enzymol 105: 352-358, 1984.

26. Choi JH, Choi AY, Yoon H, Choe W, Yoon KS, Ha J, Yeo EJ and Kang I: Baicalein protects HT22 murine hippocampal neuronal cells against endoplasmic reticulum stress-induced apoptosis through inhibition of reactive oxygen species production and CHOP induction. Exp Mol Med 42: 811-822, 2010.

27. Jeong JH, Ryu DS, Suk DH and Lee DS: Anti-inflammatory effects of ethanol extract from Orostachys japonicus on modulation of signal pathways in LPS-stimulated RAW 264.7 cells. BMB Rep 44: 399-404, 2011.

28. Cho SY, Lee JH, Bae HD, Jeong EM, Jang GY, Kim CW, Shin DM, Jeon JH and Kim IG: Transglutaminase 2 inhibits apoptosis induced by calcium- overload through down-regulation of Bax. Exp Mol Med 42: 639-650, 2010.

29. Harada $\mathrm{H}$ and Grant S: Apoptosis regulators. Rev Clin Exp Hematol 7: 117-138, 2003.

30. Antignani A and Youle RJ: How do Bax and Bak lead to permeabilization of the outer mitochondrial membrane? Curr Opin Cell Biol 18: 685-689, 2006.

31. Halestrap AP, McStay GP and Clarke SJ: The permeability transition pore complex: another view. Biochimie 84: 153-166, 2002. 